\title{
"Research On Design and Manufacturing Challenges of Transmit Receive Modules Using Advanced Quality Assurance Tools and Quality Control Techniques"
}

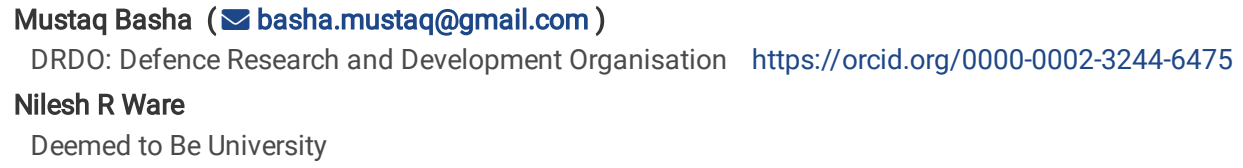

\section{Research Article}

Keywords: Quality Management, Quality Functional Deployment, Customers, Supply chain management Paper type Research paper, First Article Inspection, Quality Circles, Transmit Receiver Modules, Reliability, FMEA

Posted Date: October 21st, 2021

DOI: https://doi.org/10.21203/rs.3.rs-906041/v1

License: @ (i) This work is licensed under a Creative Commons Attribution 4.0 International License. Read Full License 


\section{Abstract}

Quality in supply chain Management is based upon a closed loop feedback system which provides solid and consistent feedback mechanism throughout the design, development and manufacturing stages of the product life cycle deployment [1,2]. To cope with the challenges of product quality design applied in supply chain management (starting from product quality design moves beyond local enterprise into supply chain, which is dynamic, trans-department, transregional and collaborative), a new design mode of product quality was generated which integrates Quality Functional Deployment (QFD) and FMEA in the product design and development process in supply chain management system for industry 4.0 requirements[3,4]. QFD provides a comprehensive, systematic approach to ensure that requirement chain captured was from need assessment to design, development and manufacturing process of the product meeting or exceeding the customer expectations among the best of the best competitors[5,6]. The objective of the Research was to study and understand the key factors that result in the successful application of QFD in dynamically varying supply chain management scenarios. QFD is not used only for a manufacturer but several customers and stakeholders to provide adequate knowledge about product/process failure modes and there impacts. In QFD each and every part, process especially the support technologies for implementing collaboration were analyzed and studied. By applying advanced tools to the system with the open source are often used to enhance the communication function, improve working efficiency and shorten the development cycle so as to respond to the fluctuation of market demands as quick as possible[7,8]. A case study is used to study the Quality function deployment technique that can be used in the processing development of designing and producing Transmit/Receive Modules(TRMs) for active phased array radars to make it more reliable and more robust than existing modules to improve customer satisfaction.

From the Pareto chart of Technical Descriptor and Importance we can see that Design capabilities and Design verification test got around $60 \%$ of importance for improvement of $T / R$ modules.

So, our focus should be to implement Reliability and quality at design phase and have to validate it much prior hardware design and development for which we need use some design tool before testing like, QFD, FMEA, Benchmarking and Ansys Sherlock which uses Physics of failure method.

\section{Introduction}

To cope with the challenges of product quality design applied in supply chain management i.e., starting from product quality design moves beyond local enterprise into supply chain, which is dynamic, trans-department, trans- regional and collaborative, the researcher used potential quality management tools as the source for data collection. Quality control tools Viz., QFD with the bench-marking is used to develop a Voice of Customer matrix. Using information from the matrix, a new customer-oriented Supply chain management programme was designed, a new design mode of product quality was generated which integrates Quality Functional Deployment (QFD) shown in figure 1.0 below.The Industry 4.0 era requires new quality management systems due to the ever increasing complexity of the global business environment[5,6].

\section{Benchmarking}

Is a continuous quality improvement process tool which is used by an organization/industry towards accessing its internal strengths and weaknesses, evaluate comparative advantages of leading competitors, identify best practices of industry functional leaders, and incorporate these findings into a strategic action plan geared to gain a position of superiority. Benchmarking can be defined as a process of comparison of some measure of actual performance against a reference or benchmark performance. There are three main aspects to the performance of a company: Efficiency, Productivity and Quality. Benchmark results are used to identify, quantify and prioritize improvement opportunities offering the greatest potential return, while highlighting areas at risk due to under-spending[3,4].

\section{Failure Mode Effective Analysis (FMEA)}

FMEA is another design tool used in SCM during product design and development process in supply chain management system. FMEA is an excellent tool for evaluating the potential failures and risks throughout the design, process and service stages as shown in figure 3.0. It helps in quality improvement, defect reduction and on time delivery. Despite the importance of FMEA in improving the product quality, studies using FMEA approach for the supply chain network are notably lacking, highlighting the importance of this research $[10,11]$.

\section{Research Methodology}

A case study of fabrication of Transmit Receive Modules (TRMs) PCBs as a platform for conducting research through data collection, analysis, challenges faced during fabrication and implementation will be discussed in this paper. The PCB's are commonly used for various bands of Active Array Antenna Design (AAAU). However they belong to category of the customized products, where each customer has their own product design specifications to suit the required product assembly. It means, unlike other unified products, they cannot be reused, even if large quantities of goods are returned. The nonconforming PCBs have to be scrapped in the majority of situations, as they cannot be repaired or re-manufactured to suit the specifications. This serious quality issues during the design and manufacturing not only creates huge loss for the manufacturer, but also the rest of supply chain network by impacting on the lead-time and customer satisfaction. The case company operates with the global customers and hence it is critical to reduce the potential failures and ensure on time delivery to remain competitive in market. This reflects the complex and competitive nature of supply chain network for the PCB products[9,10]

The research shows by designing an engineering instrument that can identify the real needs of customers and appropriate responsive activities of an industrial plant with the integration of QFD (Quality Function Deployment) along with bench-marking and FMEA (Failure Mode and Effects Analysis), and by 
focusing on application of research and development process. The study results and the experimental model application with the normal process of the plant in the case study indicated that the model was able to identify and link and the relationship between the real needs of customers and factors affecting the process in the form of points that can be ordered and classified to determine which factors having the highest impacts on the process[12,13]. It was also found that the results of the implementation of the project at the plant in the case study enabled an increase of efficiency in solving problems through the factors identified as having impacts as shown in figure 4.0 below.

\section{Findings:-}

The researchers outline a practical solution to the problem on Design challenging environment of Dynamically Varying Supply Chain Management System which satisfy the main expectations of potential employers (customers) strengthening the link in SCM.

\section{Research limitations / Implications:-}

The study is specifically concerned with the design of an SCM tools addressing the dynamic behaviour of dynamically varying supply chain management system.

Practical implications - The application of QFD and FMEA as a joint analysis tool is an interesting approach in addressing the challenges in the filed of dynamically varying supply chain management system. A case study was taken up to study the effect and was concluded that this new programme with advanced quality tools has successfully meets or exceeds customer/employer expectations and requirements.

\section{Case Study: Research On Design And Manufacturing Challenges Of Transmit Receive Modules Using Qc Tools:}

The Transmit/Receive Modules (TRMs) are the basic building blocks for active phased arrays. In transmit mode, the T/R modules receive the Radio Frequency (RF) signal from RF signal generator, amplify it and transmit the amplified signal to antenna elements. In receive mode, the T/R Module receives a signal from antenna element and provides low noise amplification of the signal.

Four numbers of T/R modules are housed in a single package called as the Quad-TRM or QTRM. However, the QTRM is operating at X-band frequency and called as X-Band QTRM. The QTRM is a hermitically sealed unit. Each T/R module of QTRM can be channeled inside with metallic walls between RF blocks in order to minimize coupling effects between adjacent T/R Module paths. The QTRM should be controlled by QTRM controller (FPGA based controller). Figure 1 shows functional block diagram of the QTRM. The layout of QTRM is shown in Figure 2. The functional block diagram of a single T/R channel in a QTRM is shown in the Figure 3.

The basic functional block diagram of a transmit/receive (T/R) module with a distributed transmitter. Amplification, phase shifters, and attenuators are required at each antenna element to electronically steer the beam and shape the antenna pattern. Additionally, each element must be protected from electromagnetic damage, which can be caused by other systems or reflected energy. The transmitter and receiver must also be connected to a common radiating element. The first amplifier in the receive chain needs to amplify small signals and generate a minimum amount of noise to provide maximum sensitivity. The last amplifier in the transmit chain needs to efficiently generate a high- power level. These conflicting requirements, along with the unidirectional performance of amplifiers, often lead to the use of separate amplifiers for the transmitter and receiver. The phase shifter and attenuator are bidirectional and can satisfy both transmit and receive functions. The basic electronic requirements at each element of the phased array can be achieved using the layout shown in Fig. 5. This setup constitutes the basic functionality commonly referred to as a T/R module. This block diagram assumes that the receive and transmit functions are not simultaneous. HYBRID VERSUS MMICs Cost and Performance The microwave components in a T/R module are realized as monolithic microwave integrated circuits (MMICs) or hybrid circuits incorporating discrete transistors. MMICs allow all of the passive components (inductors, capacitors, resistors, and transmission lines) to be fabricated on the semiconductor wafer along with the active devices (transistors, diodes, etc.). Hybrid assembly techniques use discrete parts for capacitors, inductors, and resistors, which are then integrated with the transistors using microelectronic interconnection and assembly techniques. A MMIC will cost more than the value of its active devices because of the increased semiconductor size and the complex integration of the passive components.

The new approach proposed to be used against conventional approach by subjecting the product to Accelerated Life Test with an intention to evaluate product reliability. Before bringing a Transmit/Receive Modules (T/R Modules) to the laboratory, we can develop simulation model. With this model, one can accurately identify design and assembly flaws. Creating simulated environment which is more appropriate to the real field environment is easier moreover simulation can be done by taking whole physical environmental parameters acting at once. Software simulation will interpret Physics of failure for targeted life. The outcome of this simulation is accurate when compare to conventional methods. Further, it will be economic and speedy. After all, this kind of testing has played a key role in the evolution of today's highly-reliable products. Instead, this examination of certain weaknesses in classical environmental testing can be helpful in understanding how new testing methods, in particular Accelerated Life testing can lead to even greater levels of product quality and reliability needs.

However, it is mandatory to perform laboratory test which ensures reliability and life. Verification and validation can be carried out on the module before bringing in to practice. This can be done using suitable test standards and using advanced testing machineries and searching for possibilities of integrating two or more environmental parameters which will enhance common mode failures identification and also bring the statistical confidence levels narrower. 
T/R modules are a performance, reliability, and cost driver for future phased array antenna applications. Semiconductor, packaging, and assembly technologies all play critical roles in determining the performance, reliability, and cost of T/R modules. The packaging design process should consider the effects on both semiconductor and assembly techniques to ensure that the best overall product is achieved. Trade-offs between performance, cost, and reliability must also be carefully considered for successful packaging development.

\section{Objectives Of Quality Functional Deployment}

To apply Quality Function Deployment technique to translate customer requirements into designing and producing transmit/receive modules for active phased array radars to make it more reliable and more robust than existing modules.

\section{Introduction}

Quality function deployment (QFD) is a planning tool that focuses on designing quality into a product or service by incorporating customer needs. It is a systems approach involving cross-functional teams (whose members are not necessarily from product design) that looks at the complete cycle of product development. This quality cycle starts with creating a design that meets customer needs and continues on through conducting detailed product analyses of parts and components to achieve the desired product, identifying the processes necessary to make the product, developing product requirements, prototype testing, final product or service testing, and finishing with after-sales troubleshooting.

QFD is customer driven and translates customers' needs into appropriate technical requirements in products and services. It is proactive in nature. Also identified by other names-house of quality, matrix product planning, customer-driven engineering, and decision matrix. It evaluates competitors from two perspectives, the customer's perspective and a technical perspective. The customer's view of competitors provides the company with valuable information on the market potential of its products. The technical perspective, which is a form of benchmarking, provides information on the relative performance of the company with respect to industry leaders. This analysis identifies the degree of improvements needed in products and processes and serves as a guide for resource allocation.

\section{Main Purpose of QFD}

(a) To get higher quality products to market faster and at a lower cost.

(b) To achieve customer driven product design.

(c) To provide a tracking system for future design or process improvements.

\section{Benefits of using the QFD process}

(a) Creates a customer driven environment.

(b) Reduces the cycle time for new products.

(c) Uses concurrent engineering methods.

(d) Reduces design to manufacture costs (fewer changes).

(e) Increases communications through cross functional teams.

(f) Creates data for proper documentation of engineering knowledge.

(g) Establishes priority requirements and improves quality.

\section{QFD Process: House of Quality_(}

- Quality Function Deployment (QFD) uses a matrix format to capture a number of issues that are vital to the planning process. The QFD product/ service development process or methodology is based on the development of a sequence of matrices known as "House of Quality". The house of quality is so named because of the image used in its construction.

- The use of matrices is the key to the building of the house. The primary matrix in the house of the quality is the relationship matrix between the customer needs or wants and the design features and requirements.

- The House of Quality Matrix is the most recognized and widely used to achieve higher customer satisfaction. In other words, it is a kind of conceptual map that provides the means for inter-functional planning and communication. It is constructed mainly to analyze and translate the customer requirements "What's" into technical requirements "How's"

The basic description of house of quality, shown in the Figure 4.0, is listed above: -

a) The left side of the house has the customer needs. 
b) The ceiling has the design features and technical requirements.

c) The right side contains the customer priorities (comparisons).

d) The foundation contains the benchmarking, target values.

e) The roof of the house contains a matrix describing the relationship between design features.

- In order to construct the House of Quality, QFD process need to be followed and the steps are enumerated the fig-

The first phase in the implementation of the Quality Function Deployment process involves putting together a "House of Quality". There are 11 building steps for House of quality. The steps for building the house of quality for the project are as enumerated in subsequent paragraphs.

\section{Customer Requirements- Voc Or "whats"}

In order to design and produce transmit/receive modules for active phased array radars which is able to satisfy customer needs, the customer requirements are required to be collected. In this step, the market segment required to be analyzed during the process for the project was determined and also the identification of customers was undertaken.

Table 1.0 Customer Requirements - VOC or "WHATs"

\begin{tabular}{|c|c|}
\hline SI no & Customer requirement \\
\hline 1 & Meets Technical Specification \\
\hline \multirow[t]{2}{*}{2} & Design for Quality \\
\hline & Design for Reliability (MTBF, \\
\hline 3 & Derating etc) \\
\hline 4 & Design for testability \\
\hline 5 & High Efficiency \\
\hline 6 & Thermal Stability \\
\hline 7 & Less power consumption \\
\hline 8 & Light in weight \\
\hline 9 & Ease in Maintenance \\
\hline
\end{tabular}

\section{Customer Importance Ratings.}

The selected customer's requirements were ranked on the basis of Customer feedback collected through survey. In the survey, the customer rated the importance of each requirement on a scale from 1- 5, with 5 being most important and 1 being less important. For calculation of Importance rating of all customers requirement statistical method MODE is used.

\section{Table 2.0 Customer Importance Ratings}

\begin{tabular}{|c|c|c|c|c|c|c|c|c|c|}
\hline & $\begin{array}{l}\text { Meets Technical } \\
\text { Specification }\end{array}$ & $\begin{array}{l}\text { Design } \\
\text { for } \\
\text { Quality }\end{array}$ & $\begin{array}{l}\text { Design for } \\
\text { Reliability } \\
\text { (MTBF, }\end{array}$ & $\begin{array}{l}\text { Design for } \\
\text { testability }\end{array}$ & $\begin{array}{l}\text { High } \\
\text { Efficiency }\end{array}$ & $\begin{array}{l}\text { Thermal } \\
\text { Stability }\end{array}$ & $\begin{array}{l}\text { Less power } \\
\text { consumption }\end{array}$ & $\begin{array}{l}\text { Light } \\
\text { in } \\
\text { weight }\end{array}$ & $\begin{array}{l}\text { Ease in } \\
\text { Maintenance }\end{array}$ \\
\hline $\begin{array}{l}\text { Customer } \\
\text { Requirements } \\
\text { (What's) }\end{array}$ & & & Derating etc) & & & & & & \\
\hline $\begin{array}{l}\text { Importance } \\
\text { Rating of customer } \\
\text { requirments }\end{array}$ & 5 & 4 & 4 & 4 & 5 & 4 & 4 & 3 & 3 \\
\hline
\end{tabular}

\section{Customer Rating of the Competitor.}

In this step the customer ratings are to be taken with respect to the competitors' product. The rating will be used to set the benchmarking of the product. The procedure has been substituted by taking the same voice of customers for competitors (AMPL, Data Pattern, BEL). In the survey, the customer rated the importance of each requirement on a scale from 1-5, with 5 being most important and 1 being less important and the statistical method MODE is used for getting the results. 


\begin{tabular}{|c|c|c|c|c|c|c|c|c|c|}
\hline & $\begin{array}{l}\text { Meets } \\
\text { Technical } \\
\text { Specification }\end{array}$ & $\begin{array}{l}\text { Design } \\
\text { for } \\
\text { Quality }\end{array}$ & $\begin{array}{l}\text { Design for } \\
\text { Reliability (MTBF, } \\
\text { Derating etc) }\end{array}$ & $\begin{array}{l}\text { Design } \\
\text { for } \\
\text { testability }\end{array}$ & $\begin{array}{l}\text { High } \\
\text { Efficiency }\end{array}$ & $\begin{array}{l}\text { Thermal } \\
\text { Stability }\end{array}$ & $\begin{array}{l}\text { Less power } \\
\text { consumption }\end{array}$ & $\begin{array}{l}\text { Light } \\
\text { in } \\
\text { weight }\end{array}$ & $\begin{array}{l}\text { Ease in } \\
\text { Maintel }\end{array}$ \\
\hline \multicolumn{10}{|l|}{ Customer Requirements (What's) } \\
\hline \multirow[t]{2}{*}{ Competitor rating 1- AMPL } & 4 & 4 & 4 & 3 & 3 & 3 & 3 & & \\
\hline & & & & & & & & 3 & 3 \\
\hline Competitor rating 2- Data Pattern & 4 & 4 & 3 & 4 & 3 & 3 & 4 & 4 & 4 \\
\hline \multicolumn{10}{|l|}{ Competitor rating 3- BEL } \\
\hline & 3 & 3 & 3 & 3 & 3 & 3 & 3 & 3 & 3 \\
\hline competitors & $\begin{array}{l}\text { Meets } \\
\text { Technical } \\
\text { Specification }\end{array}$ & $\begin{array}{l}\text { Design } \\
\text { for } \\
\text { Quality }\end{array}$ & $\begin{array}{l}\text { Design for } \\
\text { Reliability (MTBF, } \\
\text { Derating etc) }\end{array}$ & $\begin{array}{l}\text { Design } \\
\text { for } \\
\text { testability }\end{array}$ & $\begin{array}{l}\text { High } \\
\text { Efficiency }\end{array}$ & $\begin{array}{l}\text { Thermal } \\
\text { Stability }\end{array}$ & $\begin{array}{l}\text { Less power } \\
\text { consumption }\end{array}$ & $\begin{array}{l}\text { Light } \\
\text { in } \\
\text { weight }\end{array}$ & $\begin{array}{l}\text { Ease in } \\
\text { Maintel }\end{array}$ \\
\hline Benchmarking & 4 & 4 & 4 & 4 & 3 & 3 & 4 & 4 & 4 \\
\hline
\end{tabular}

\section{Technical Requirements- Voice of Engineer "Hows".}

The technical requirements are attributes about the product or service that can be measured and benchmarked against the competition. There are 5 technical requirements considered to make our product more reliable and more robust than existing modules.

Table 4.0 Voice of Engineer

\begin{tabular}{|cl|}
\hline SI no & Technical Descriptor \\
1 & Design Capabilities \\
\hline 2 & Manufacturing capabilities \\
\hline 3 & Vendor QA Process \\
\hline 4 & Design Verification Test \\
\hline 5 & Qualification Test \\
\hline
\end{tabular}

\section{Relationship Matrix.}

The relationship matrix is where the team determines the relationship between customer needs and the company's ability to meet those needs. Rating of the relationship between the customer requirements and the technical requirements was evaluated in this step and constructed a relationship matrix. The relationship matrix provides a listing of how the technical requirements represent each customer's needs on a scale of 1,3 , and 9 .

(a) 1 represents a slight or possible relationship

(b) 3 represents a moderate relationship

(c) 9 represents for a strong relationship.

Table 5.0 Relationship Matrix 


\begin{tabular}{|c|c|c|c|c|}
\hline \multicolumn{5}{|l|}{ Functional Requirements (How's) } \\
\hline \multicolumn{5}{|l|}{ Customer Requirements - (What's) } \\
\hline \multicolumn{5}{|l|}{$\downarrow$} \\
\hline Meets Technical Specificaiton & 9 & 9 & 9 & 3 \\
\hline Design for testability & 9 & 9 & 9 & 9 \\
\hline High Efficiency & & & 3 & \\
\hline Thermal Stability & & & 3 & 3 \\
\hline
\end{tabular}

\section{Difficulty, Cost and time}

The difficulty level to achieve these technical descriptors is scaled by discussing with technical team members. Similarly, estimated cost and time required for completion of the project is scaled by having a discussion with project manager.

\section{Technical Analysis of Competitor Products}

This process involves reverse engineering on the competitor products to determine specific values for competitor technical requirements. Also, to better understand the competition and engineering, a comparison of competitor technical requirement can be conducted and benchmarking of these is added in the HOQ.

\section{Table 6.0 Technical Analysis of Competitor Products}

\begin{tabular}{|c|c|c|c|c|c|}
\hline Technical & Design Capabilities & $\begin{array}{l}\text { Manufa cturing capabilit } \\
\text { ies }\end{array}$ & $\begin{array}{l}\text { Vendor QA } \\
\text { Process }\end{array}$ & Design Verificatio $n$ Test & $\begin{array}{l}\text { Quali ficati on } \\
\text { Test }\end{array}$ \\
\hline \multicolumn{6}{|c|}{ Requirements (How's) } \\
\hline \multicolumn{6}{|l|}{ Competitor } \\
\hline rating 1- AMPL & 4 & 3 & 3 & 2 & 3 \\
\hline \multicolumn{6}{|c|}{ Competitor rating 2-Data Pattern } \\
\hline & 3 & 4 & 3 & 3 & 2 \\
\hline \multicolumn{6}{|c|}{ Competitor rating 3-BEL } \\
\hline & 4 & 4 & 3 & 3 & 3 \\
\hline
\end{tabular}

\section{Correlation Matrix}

The development of technical correlations was carried out and assigned in the roof of the house of the quality. Examination of how each of the technical requirements is impacting other can be undertaken from this matrix and documentation has to be done on strong negative relationships between technical requirements and work. The correlations were formulated to determine the relationship between the "How's" and to show what "How's" influence each technique. These indications show that technical elements affect the performance of each other's, which is represented by the sign,

\section{Table 7.0 Correlation Matrix}

\begin{tabular}{|lllll|}
\hline++ & + & $\cdot$ & - & - \\
Strong Positive & Positive & No correlation & Negative & Strong Negative \\
\hline
\end{tabular}




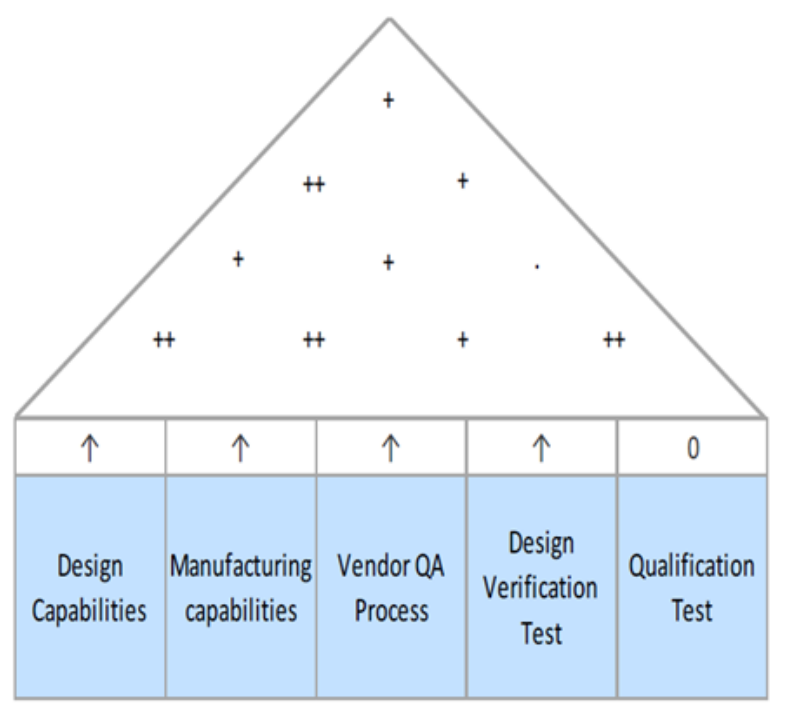

\section{QFD Results and Inference}

- Quality function deployment technique can be used in the processing development of designing and producing transmit/receive modules for active phased array radars to make it more reliable and more robust than existing modules to improve customer satisfaction.

- From the Pareto chart of Technical Descriptor and Importance we can see that Design capabilities and Design verification test got around $60 \%$ of importance for improvement of T/R modules.

- So, our focus should be to implement Reliability and quality at design phase and have to validate it. For which we need use some design tool before testing like, Ansys Sherlock which is uses POF method.

\section{Summary And Conclusions}

The methodology followed to carry out the research being reported was started by conducting literature survey on the aspects of linking QFD along with bench-marking and FMEA leading to innovation towards addressing dynamically challenging market environment followed with an experimental case study. However no research has so far been conducted to link these models Viz., QFD.bench- marking and FMEA in supply chain management. This paper present the research work carried out to study the impact of above said tools in supply chain management system. The research also provides directions for the effective assessment of process quality risks within SCM network. The tools like QFD design and FMEA represents an effective methodology for improving the process quality, product quality and reliability by prioritizing the failure problems throughout the process of design , development and production. The work also demonstrate how results could provide comprehensive understanding of the failure modes in design , development and manufacturing processes. To cope with the challenges of product quality design applied in supply chain management (starting from product quality design moves beyond local enterprise into supply chain, which is dynamic, trans-department, trans- regional and collaborative); A new design mode of product quality was generated which integrates Quality Functional Deployment (QFD) and FMEA in the product design and development process in dynamically varying supply chain management system. The research evidently shows the need for focus on processes and their associated risks also emphasized on the need for assuring the quality performance in the global supply chain network.

\section{Declarations}

Funding: DRDO LRDE Lab , Bangalore

\section{Conflicts of interest/Competing interests- N/A}

Availability of data and material: Available

Code availability: N/A

Authors' contributions: A unique first time research was carried out on Design and manufacturing challenges on production of active TRMs for phased array radar technology by effective utilization of QC and QA tools.

Ethics approval: Yes

Consent to participate: Yes

Consent for publication: Free Journal

Acknowledgement:- 
The authors of this paper place on record their sincere thanks and deep sense of gratitude to the Director Electronics and Radar Development Establishment (LRDE) Sri SS Nagaraj Distinguished Scientist, DRDO and Department of Technology Management, Defence Institute of Armament Technology (DIAT)

Deemed to be University for providing opportunity to present this paper in this POMS International conference, Dec 2019 Mumbai.

\section{References}

1. Lee S, Lim S (2018) Living innovation: from value creation to the greater good. Emerald Publishing Limited, Bingley

2. Jacob D (2017) Quality 4.0 impact and strategy handbook: getting digitally connected to transform quality management. LNS Research, Cambridge

3. Lee S, Youn B (2015) Industry 4.0 and prognostics and health management. Noise Vib 25(1):22-28

4. Lee S (2018) Innovation: from small “i” to large "I”. Int Journal Quality Innovation 4(2):1-3 :Google Scholar Haq AN, Boddu V(2014), “Analysis of enablers for the implementation of supply chain management using an integrated fuzzy QFD approach", Journal of Intelligent Manufacturing, pp. 1-12

5. Adiano C, Roth AV (1994), 'Beyond the House of Quality: Dynamic QFD'

6. Benchmarking: An Intentional Journal, Vol. 1, No. 1, pp. 25-37

7. Akao Y (1990) Quality Function Deployment: Integrating Customer requirements into Product Design. Productivity Press, Cambridge

8. Akao MA Y. and Mazur GH (2003) 'The leading edge in QFD: Past, Present and Future'. International Journal of Quality Reliability Management 20(1):2035

9. Al-Mashari M, Zairi M, Ginn D (2005) 'Key enablers for the effective implementation of QFD: a critical analysis'. Industrial Management \& Data 10. System, Vol. 105, No. 9, pp. 1245-1260

11. Augusto P, Miguel C (2007) 'Innovative new roduct development: a study Of selected QFD case studies'. The TQM Magazine 19(6):617-625

12. Gilchrist W (1993) Modelling failure modes and effects analysis. International Journal of Quality Reliability Management 10:16-23

13. Bendell T, Penson R, Carr S (1995) 'The quality gurus - their approaches described and considered'. Managing Service Quality 5(6):44-48

14. Bosch GV, Enriquez FT (2005) 'TQM andQFD: exploiting a customer complaint management system'. International Journal of Quality Reliability Management 22(1):30-37

\section{Figures}

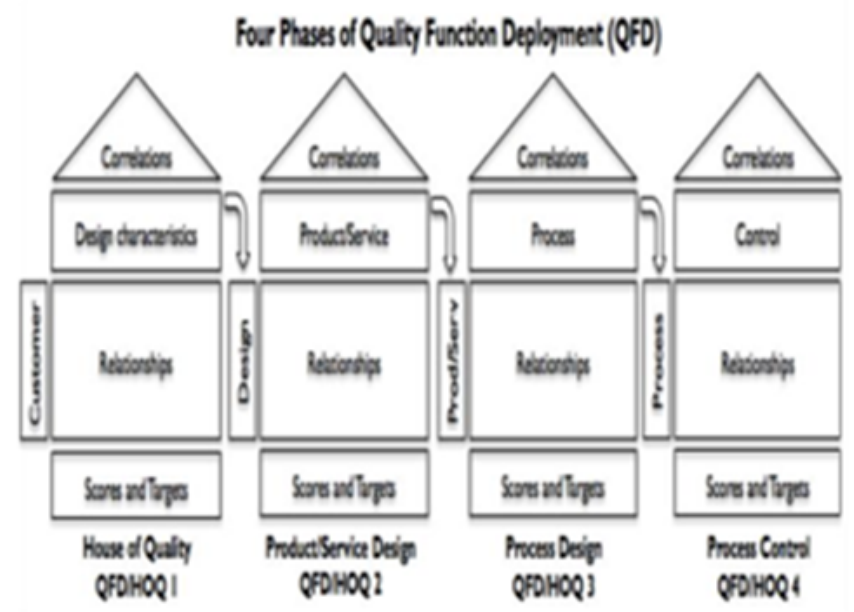

Figure 1

Phases of QFD in SCM System 


\section{STEP1}

Measure your

Performance

Establish your sustainability baseline and quantify your progress
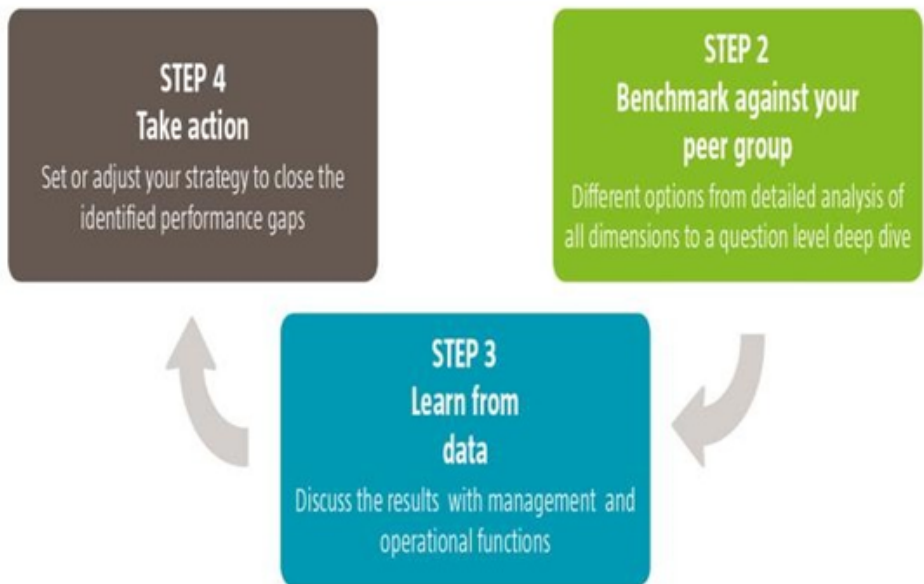

Figure 2

Bench Marking Model

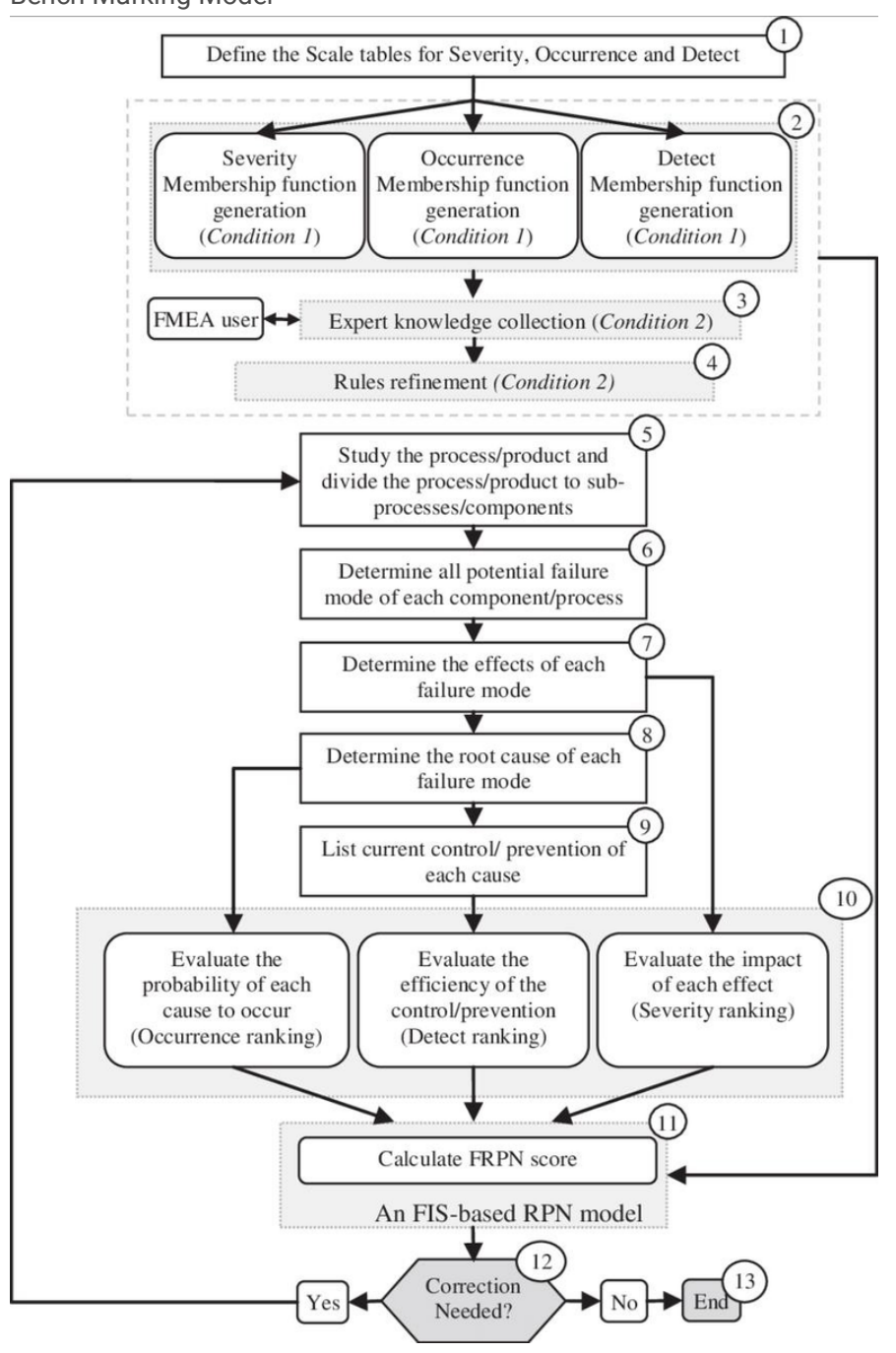

Figure 3 
Failure Mode Effective Analysis

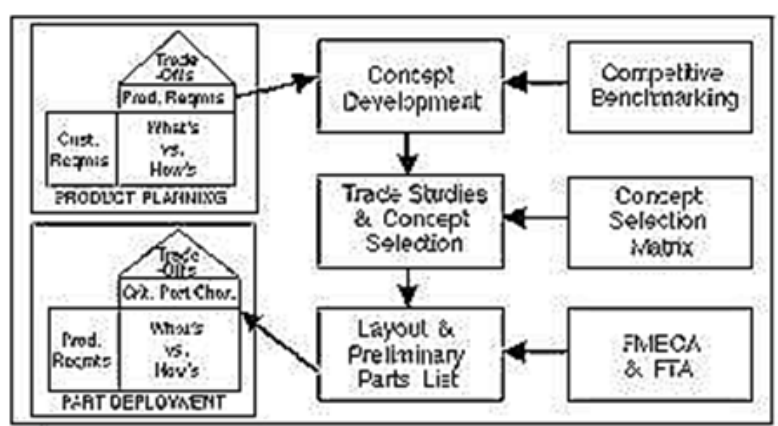

Figure 4

QFD with Bench-marking and FMEA in SCM

$$
\text { RXOUT/TXIN DIGITLINOUT }
$$

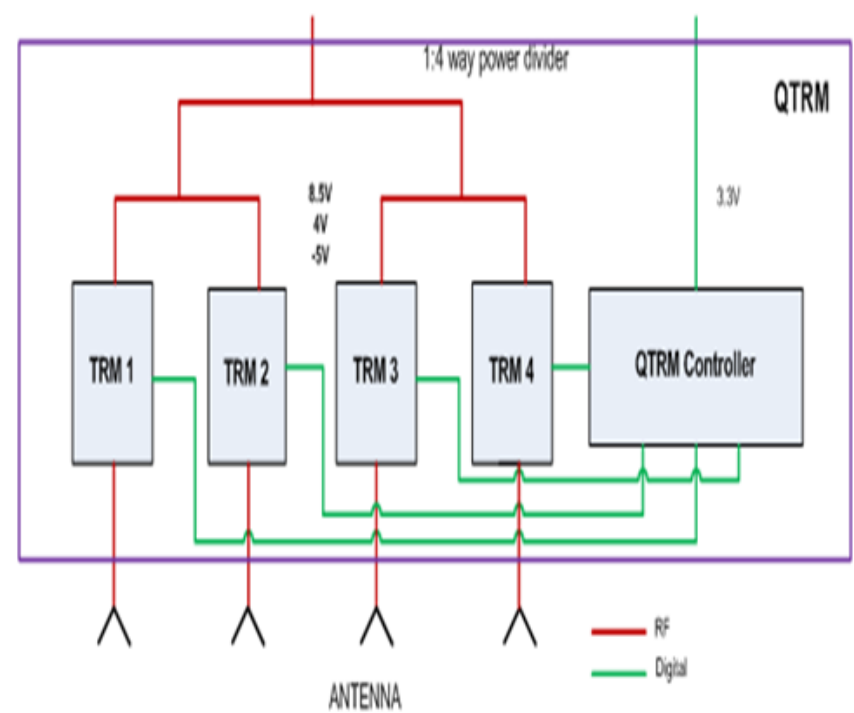

Figure 5

QTRM functional blocks

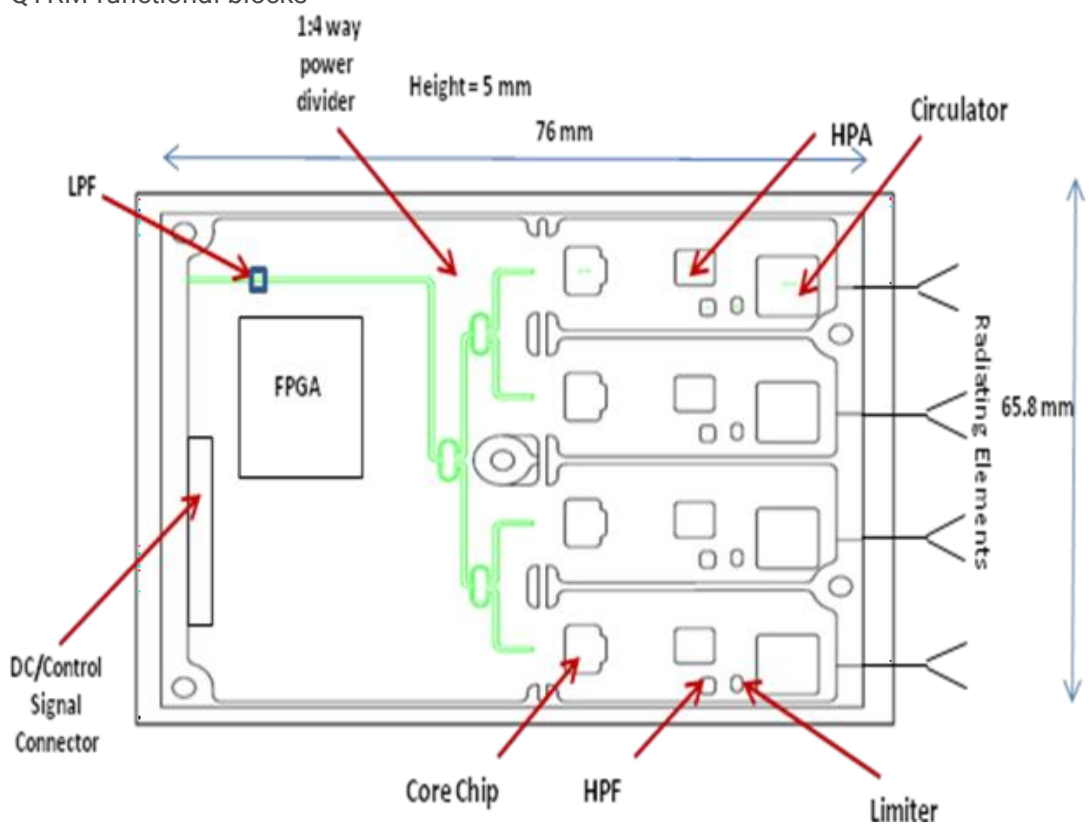

Figure 6 
Layout of QTRM

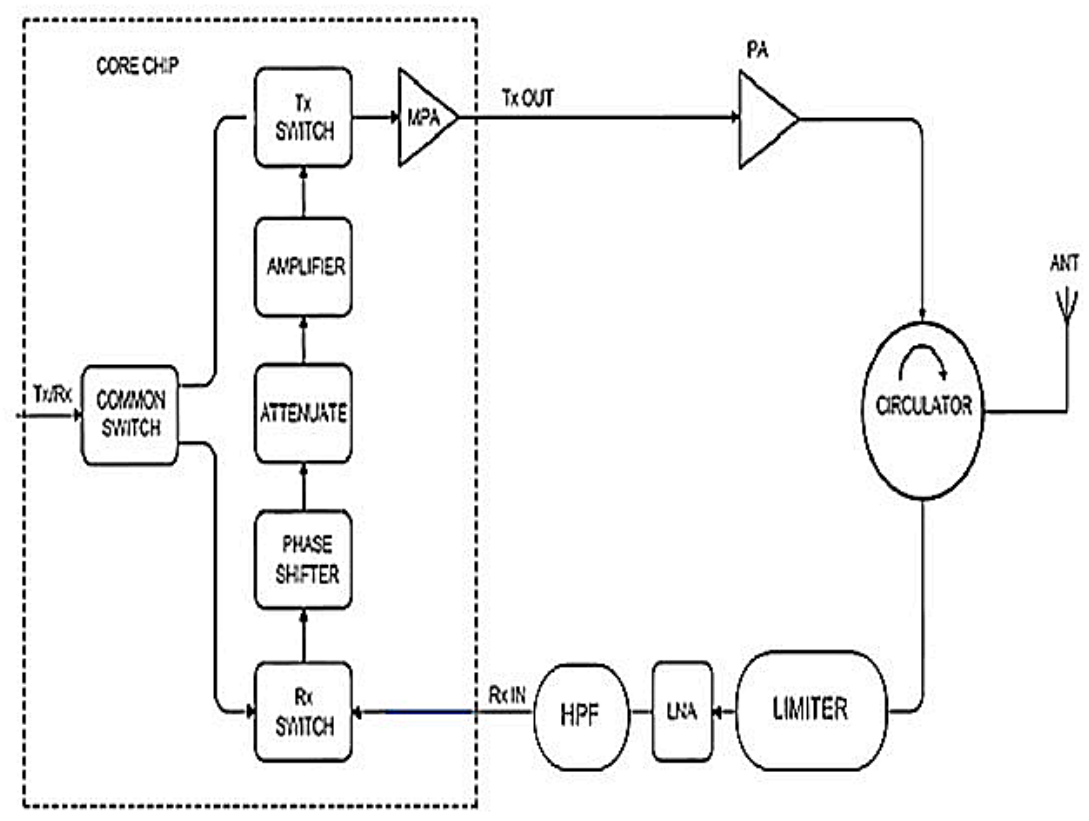

Figure 7

Single TRM channel RF functional flock diagram inside a QTRM

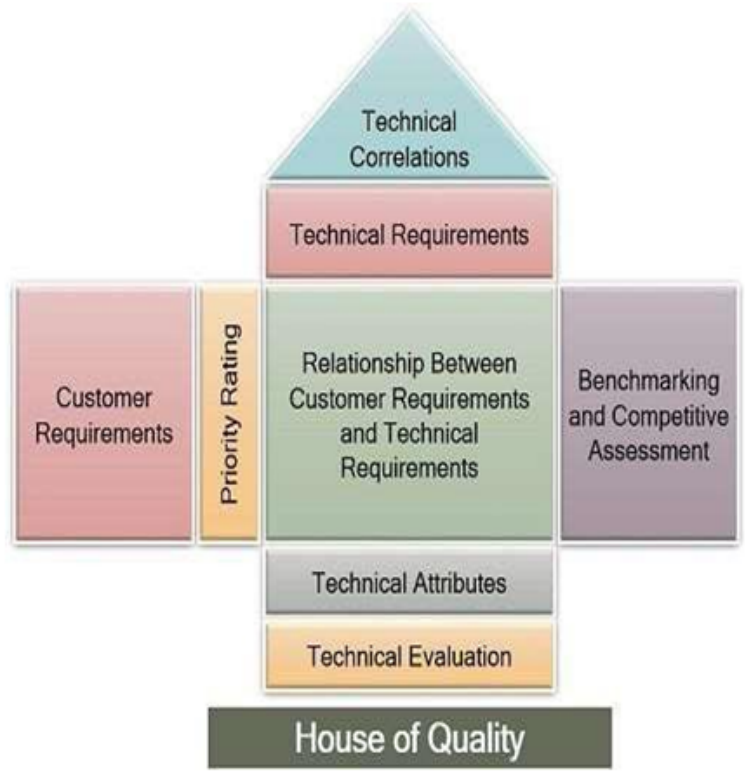

Figure 8

QFD Matrix: The house of quality 
Customer Voice Collection

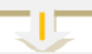

Customer Importance Rating

Customer rating of impetition

1

Technical Requirements

I

Direction of Improvement

I

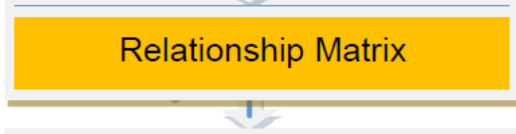

Technical Analysis of

1

Target Values

1

Correlation Matrix

Importance

Figure 9

QFD Process: Voice of Customer 


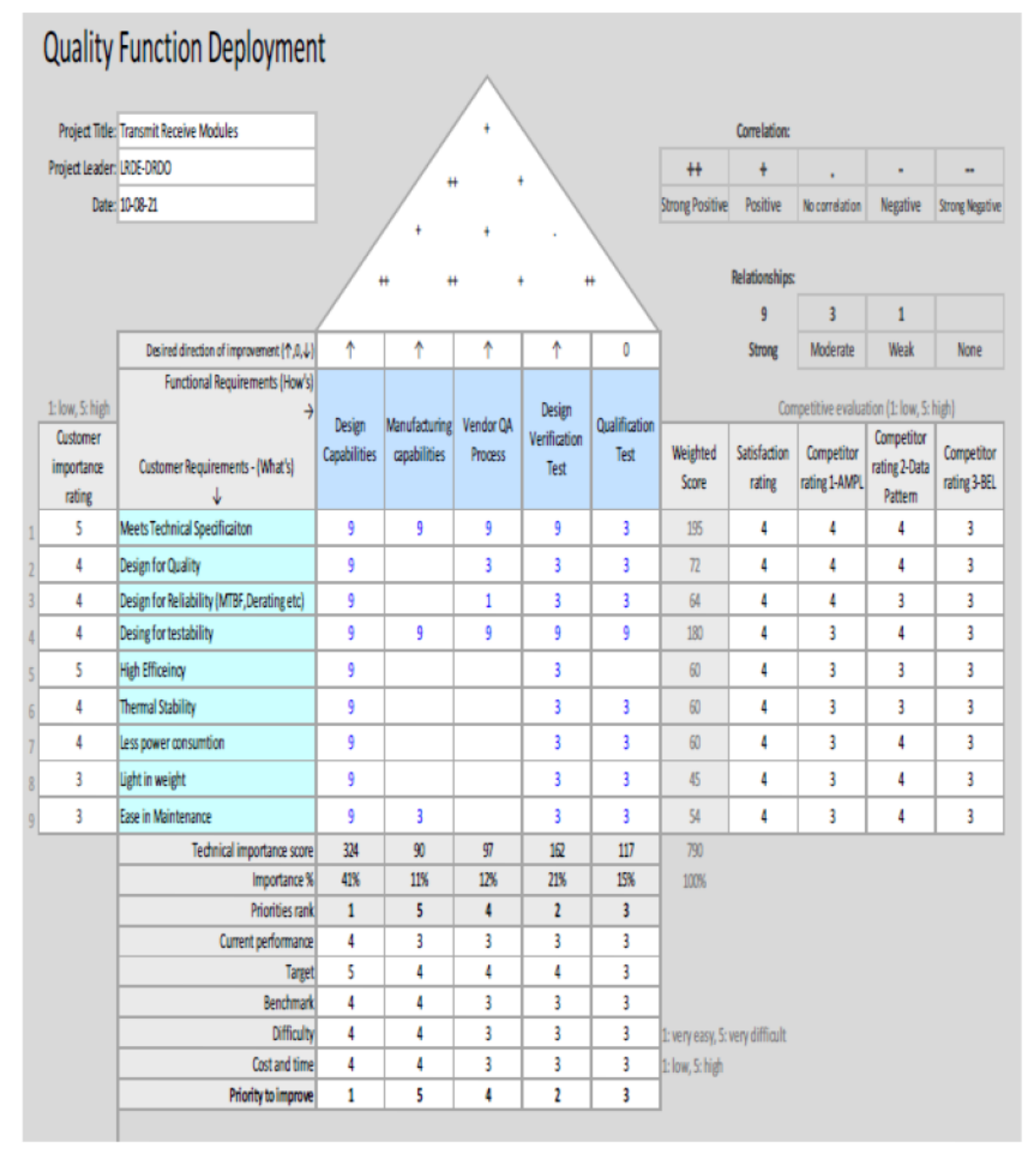

\section{Figure 10}

QFD Process: House of Quality 


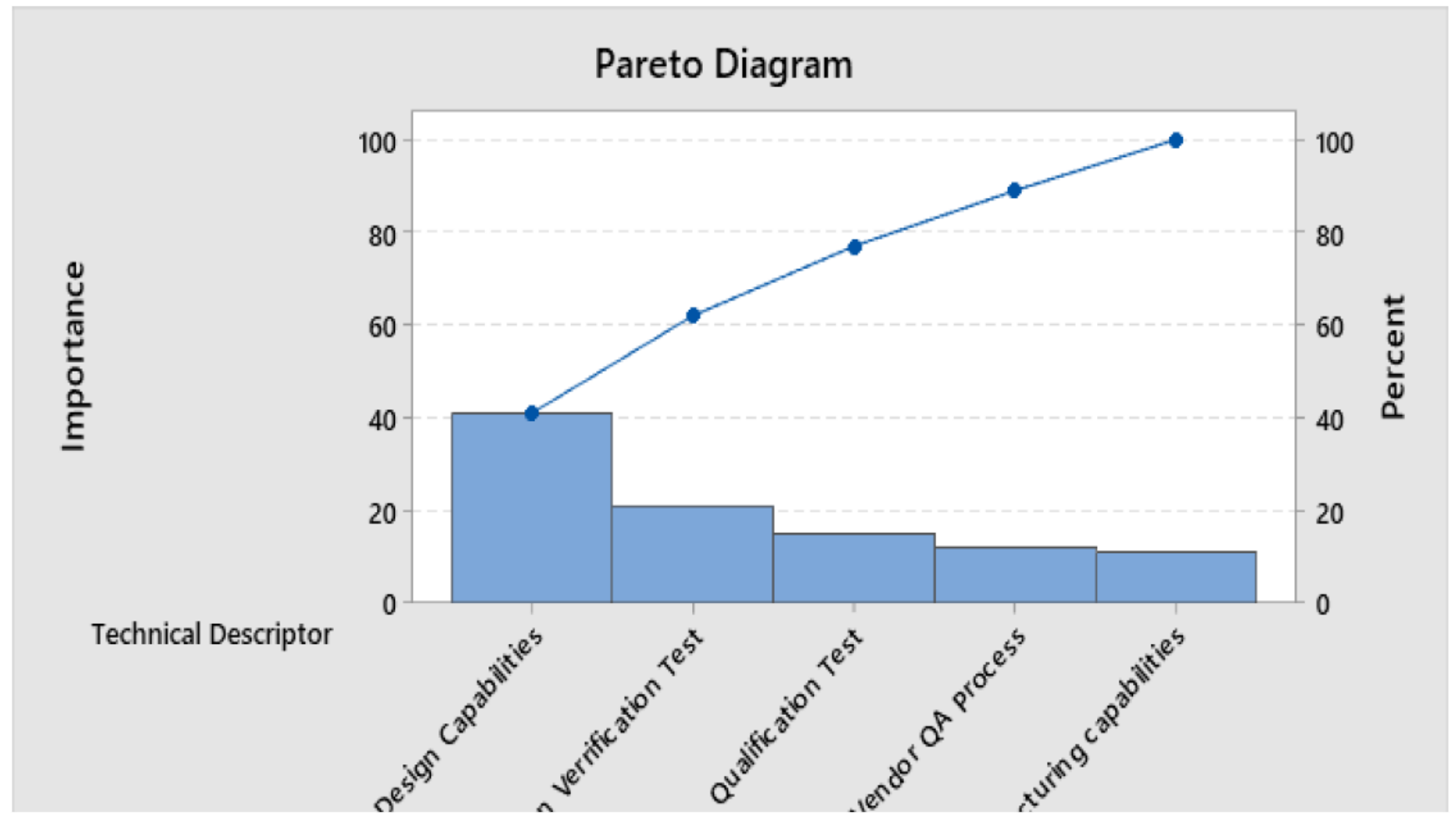

Figure 11

Pareto chart for Technical Descriptors 